\section{Codesigning a public health approach to preventing firearm-related suicide deaths with rural communities}

Dr. Gomez and colleagues offered much-needed insight into the geographic patterns of firearm injuries in Ontario, Canada. ${ }^{1}$ They found that assault-related injuries were concentrated in cities, and rates of self-harmrelated injuries were highest in rural areas. We support the authors' call for context-specific public health interventions and wish to offer an additional perspective on rural suicide prevention and the role of guns in rural communities.

Although the authors did not evaluate differences by ethnic origin, the north-south disparities in self-harm may reflect differences in suicide rates between Indigenous and non-Indigenous populations. Compared with southern areas, northern regions in Canada have proportionately larger Indigenous populations; suicide rates tend to be higher in many northern areas, including in Ontario. ${ }^{2-4}$ Assessing possible differences in rates of self-harm between Indigenous and non-Indigenous peoples within rural or northern areas may help further tailor interventions.

The limited data about household firearm ownership in Canada show that the prevalence is higher in rural areas, and in the territories and Atlantic provinces. ${ }^{5,6}$ Although we recognize the relationship between firearm access and suicide, ${ }^{7}$ most firearms in rural households are rifles and shotguns, ${ }^{5}$ and hunting is the main reason many rural families in Canada own a gun. ${ }^{5,6}$ Given the high rates of food insecurity in rural and Indigenous communities, ${ }^{8}$ it is important to understand that firearms support household access to country foods such as birds, moose, caribou and seal. As a matter of equity, this context needs to be part of discussions about the role of firearm policy in suicide prevention.
Local interventions that support the safe storage of firearms ${ }^{9}$ may offer practical opportunities for suicide prevention in rural and northern areas. This could include counselling for safe firearm storage when people who are suicidal visit the emergency department; ${ }^{10}$ providing households with gun cabinets; ${ }^{11}$ setting up community firearm storage lockers; or creating voluntary, out-of-home firearm storage plans with retailers or law enforcement agencies for people who are at acute risk of self-harm. ${ }^{12}$ In Nunavut, for example, the territorial government established a firearm safety program, which involved distributing free trigger locks via hunting associations, wildlife offices and police detachments. ${ }^{13}$

From a public health perspective, it is important to avoid viewing rurality as a homogeneous context. A key direction for suicide prevention research in Canada is to assess the effectiveness of firearm safety interventions in diverse rural settings. We hope the study from Ontario ${ }^{1}$ will support efforts to prevent firearm-related suicide with a process that is not only "rural proofed," 14 but also designed by the families and stakeholders who have the most to gain from rural suicide prevention.

\section{Nathaniel Pollock PhD}

Postdoctoral fellow, School of Public Health,

University of Alberta, Edmonton, Alta.

\section{Margo Wilson MD}

Emergency physician, Discipline of Emergency

Medicine, Faculty of Medicine, Memorial

University, St. John's, NL

\section{Yordan Karaivanov MD}

Family physician and chief of staff, Labrador Health Centre, Labrador-Grenfell Health, Happy Valley-Goose Bay, NL

\section{Nicole Power MASP}

Policy, planning and research analyst, Department of Research and Innovation, Eastern Health, St. John's, NL

\section{Charlene Reccord PhD}

Clinical research scientist, Department of Research and Innovation, Eastern Health, St. John's, NL
- Cite as: CMAJ 2020 December 14;192:

E1811. doi: $10.1503 / \mathrm{cmaj} .77311$

\section{References}

1. Gomez D, Saunders N, Greene B, et al. Firearmrelated injuries and deaths in Ontario, Canada, 2002-2016: a population-based study. CMAJ 2020;192:E1253-63.

2. Pollock NJ, Mulay S, Valcour J, et al. Suicide rates in Aboriginal communities in Labrador, Canada. Am J Public Health 2016;106:1309-15.

3. Skinner R, McFaull S, Draca J, et al. Suicide and self-inflicted injury hospitalizations in Canada (1979 to 2014/15). Health Promot Chronic Dis Prev Can 2016;36:243-51.

4. Pollock NJ, Healey GK, Jong M, et al. Tracking progress in suicide prevention in Indigenous communities: a challenge for public health surveillance in Canada. BMC Public Health 2018;18:1320.

5. Block R. Firearms in Canada and eight other western countries: selected findings of the 1996 International Crime (Victim) Survey. Ottawa: Canada Department of Justice; 1998.

6. GPC Research. Fall 2001 estimate of firearms in Canada: report on findings submitted to the Public Policy Forum. Ottawa: Canadian Firearms Centre; 2002.

7. Anglemyer A, Horvath T, Rutherford G. The accessibility of firearms and risk for suicide and homicide victimization among household members: a systematic review and meta-analysis. Ann Intern Med 2014;160:101-10.

8. Tarasuk V, Fafard St-Germain A-A, Mitchell A. Geographic and socio-demographic predictors of household food insecurity in Canada, 201112. BMC Public Health 2019;19:12.

9. Monuteaux MC, Azrael D, Miller M. Association of increased safe household firearm storage with firearm suicide and unintentional death among US youths. JAMA Pediatr 2019;173:657-62.

10. Miller M, Salhi C, Barber C, et al. Changes in firearm and medication storage practices in homes of youths at risk for suicide: results of the SAFETY study, a clustered, emergency departmentbased, multisite, stepped-wedge trial. Ann Emerg Med 2020;76:194-205.

11. Grossman DC, Stafford HA, Koepsell TD, et al. Improving firearm storage in Alaska Native villages: a randomized trial of household gun cabinets. Am J Public Health 2012;102:S291-7.

12. Kelly T, Brandspigel S, Polzer E, et al. Firearm storage maps: a pragmatic approach to reduce firearm suicide during times of risk. Ann Intern Med 2020;172:351-3.

13. Nunavut's free trigger locks for firearms campaign comes to Iqaluit. CBC News North 2016 Jan. 20. Available: www.cbc.ca/news/canada/ north/iqaluit-firearm-trigger-lock-1.3412142 (accessed 2020 Oct. 30).

14. Swindlehurst HF, Deaville JA, Wynn-Jones J, et al. Rural proofing for health: a commentary. Rural Remote Health 2005;5:411.

Competing interests: None declared. 